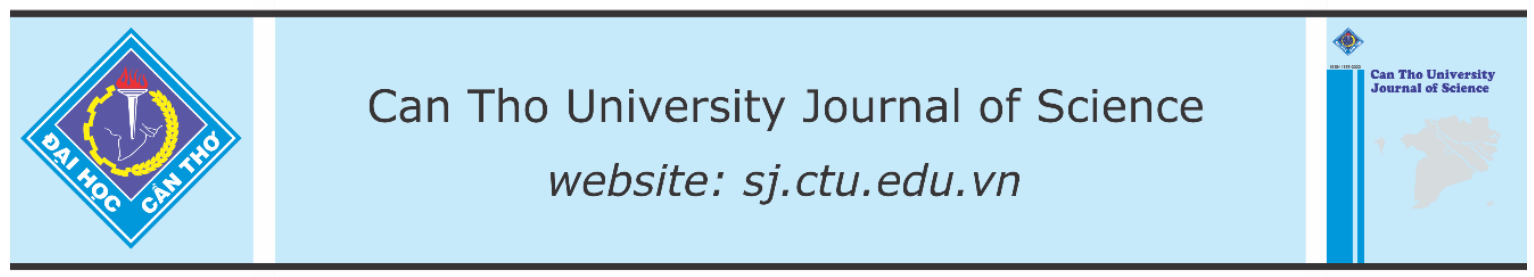

DOI: 10.22144/ctu.jen.2021.008

\title{
Effects of computer-based feedback and formative assessment on learning outcomes
}

\author{
Ngo Van Thien* \\ General Education Department, Cao Thang Technical College, Vietnam \\ *Correspondence: Ngo Van Thien (email: ngovanthien@caothang.edu.vn)
}

\section{Article info.}

Received 15 Sep 2020

Revised 26 Dec 2020

Accepted 31 Mar 2021

\section{Keywords}

Backward design course, computer based feedback and formative assessment, learning outcome, student response system

\begin{abstract}
The purpose of the study is to examine the effect of student response systems in computer-based feedback and formative assessment on learning outcomes. The backward design course is a tool to be applied for collecting necessary assessment evidence. The quasi-experimental research design involves collecting pretest and posttest data on students assigned to the control and the experimental group. The sample group consists of $148 \mathrm{col}-$ lege students randomly selected from two of the eight classes of electrical and electronics students at Cao Thang Technical College in Ho Chi Minh City, Vietnam. The research findings revealed that the experimental group, in which student response systems were applied, got better results than the control group, who did not apply them. Results show that using student response systems for technology-based feedback and formative assessment is vital and meaningful not only for teachers but also for students in the teaching and learning process.
\end{abstract}

\section{INTRODUCTION}

Assessment is an integral part of the educational process. There are some types of assessments in the educational process such as formative assessment, and summative assessment (Dixson \& Worrell, 2016). Formative assessment plays a role important in the teaching and learning process as it helps students to achieve the learning goals. In effect, Hattie (2012) mentioned that formative assessment was rated as one of the most effective methods to encourage students to engage during their learning. Besides, using feedback and formative assessment also aims to fill the gap between the students' current knowledge and desired learning goals by giving feedback to learners (Sahin, 2019).

In the $21^{\text {st }}$ century, with new technologies developed, teachers are multiple opportunities to collect a variety of assessment data in the classroom in order to know how students are progressing in the learning process. Based on students' current progress level, teachers determine what adjustments might be made to help different students and identify the strengths and weaknesses of learners in relation to the desired learning outcomes. Moreover, using intelligent and adaptive technologies in classroom affects the virtual learning environment, including students' interest and engagement, peer interaction, active and collaborative learning (Spector et al., 2016). As a result, using technology for collecting students' responses in real-time in order to check student's current knowledge is essential in the teaching and learning process.

Student response system (SRS) is an interactive remote answering device (Heaslip et al., 2014). In a large classroom, applying SRS to technology device, i.e., computer, iPad, a smartphone with internet connection for feedback and formative assessment is essential because the SRS gives feedback to students in real-time in order to help students foster 
their self-regulated learning in relation to learning outcome. In the context of teaching and learning in higher education in Vietnam, there are some of research on formative assessment (Ngo Van Thien, 2017), but feedback and formative assessment with support of technology is not developed neither documented. Thus, this research aims to investigate the effect of integrating student response system into computer-based feedback and formative assessment on students' learning outcomes.

\section{LITERATURE REVIEW}

In curriculum development approach, backward design course plays a vital role in the teaching, learning and assessment process. The instructional design course development facilitates students to meet learning goals. In a learning-centered approach, the backward design was used to embed assessment during the teaching and learning. This approach has three stages: the first stage is related to identify intending outcomes, the next stage is to plan the assessments, and the last stage is to list the learning and teaching activities to lead students to the desired results (Wiggins \& McTighe, 1998).

In the learning and teaching process, some assessments are used i.e., diagnostic assessment, formative assessment, and summative assessment. Feedback and formative assessment are a natural on-going. It encompasses the general process of collecting, synthesizing, and interpreting information. The formative assessment with feedback in real-time help students identifying strengths and weakness with a view to checking regularly on progress for meeting goals. Wiliam (2011) stated that monitoring students' progress during the teaching process is extremely important. It is therefore necessary for implementing feedback and formative assessment in the teaching process to provide high-quality evidence of learning. Additionally, feedback and formative assessment reinforce self-regulated learning strategy among students in the prospect of improving the learning process (Clark, 2012). Panadero et al. (2019) indicated that formative assessment and self-regulated learning have a close relationship. Thus, using feedback and formative assessment for the purpose of improving students' self-regulated learning is essential in the teaching and learning process.

Virtual classroom interactivity plays a crucial role of teaching and learning process. Therefore, feedback and formative assessment with helping technology are necessary for an online course. As a matter of fact, Elmahdi et al. (2018) mentioned that using technology for formative assessment improves learning and teaching activities. Moreover, in order to enhance interaction between teacher and students during the teaching and learning, the SRS was applied (Siau et al., 2006). Applying SRS into technology devices (i.e., computer, iPad, smartphone) with internet connection promotes interaction between teacher and students by posing questions and poll students' answers during teaching and learning. Beatty and Gerace (2009) discovered that technology-enhanced formative assessment (TEFA) improved student learning outcomes.

This study integrated SRS and TEFA to pose questions to students and collect their answers for the purpose of providing real-time information about student learning to both teacher and students to adjust the teaching method and learning process. Based on SRS and TEFA, the hypothesis is proposed as follows:

Integrating SRS into computer with internet connection for feedback and formative assessment improves students' learning outcome through online course.

\section{RESEARCH METHODOLOGY}

\subsection{Research context}

This study was conducted to first-year electrical and electronic students at Cao Thang Technical College in Ho Chi Minh, Vietnam. Due to the COVID-19 pandemic, the online course was done via a zoom cloud meeting, and google classroom. The learning materials were upload to google classroom such as slides of presentations, e-books. The teacher asked students to read documents at home before going to on zoom cloud meeting. The online course took place from 16 March 2020 to 25 April 2020.

\subsection{Research design}

The design used for the study a pre-test, post-test non randomized control group quasi experimental research design which consisted of two instructional groups. The independent variables were two different types of instructional approaches; instruction based on computer with internet connection for formative assessment following feedback, and teaching without using feedback and formative assessment while the dependent variable were students' academic achievement. In quasi-experimental research design, each group was given both a pre-test and a post-test, measuring the dependent 
variable before and after exposure to independent variable.

\subsection{Sample}

All first-year students of electrical and electronic faculty consist of eight classes. Two classes were chosen from eight and they were randomly assigned as experimental and control group. The sample of this study consist of 148 college students at Cao Thang Technical College (experimental group, $\mathrm{N}=$ 75 ; control group, $\mathrm{N}=73$ ). This study was carried out in the second semester, 2019-2020 academic year. All students are male with the average age range of 19.

\subsection{Teaching process}

The physics general program designed for college students at Cao Thang Technical College covers 60 teaching hours including topics such as "force and motion", "energy", "solid mechanics", and "electricity and magnetism", in which the energy topic is composed of six teaching hours. The outcome of this topic is stated as "applying energy and momentum conservation laws to solve realworld problems". The learning outcome composed of the knowledge content such as work, kinetic energy, potential energy, energy conservation, power, and collisions.

The online course was presented to both the experimental group (EG) and the control group (CG). In the EG, the SRS was used for feedback and formative assessment, whereas the CG participated in the course with formative assessment without SRS.

In order to know if students have achieved the desired results and met the learning outcome setting, the backward design method were used to guide teacher to set goal, collect assessment evidence needed to document and validate the desired learning. In this study, computer based feedback and formative assessment strategy with the support of google form. Based on the desired learning outcome, the assessment evidence needs to be collected such as work, kinetic energy, potential energy, energy conservation law, and collision.

\subsection{Instrument and data collection}

\subsubsection{Instrument}

Basing on the specific content learning outcome of the physics course at Cao Thang Technical College, the multiple-choice question (MCQ) test was designed to evaluate the students' learning goals on the topic of energy. MCQ items formats consist of four response options (e.g., one correct answer with three distractors).

The MCQ test has 20 items. It was designed on Bloom's Taxonomy including the first four-level i.e., remembering, understanding, applying and analyzing, depicted as follows:

Table 1. Question classification based on Bloom's Taxonomy for pretest and posttest

\begin{tabular}{|c|c|c|c|c|c|c|c|}
\hline & Work & $\begin{array}{r}\text { Kinetic energy and } \\
\text { work-energy theorem }\end{array}$ & $\begin{array}{r}\text { Potential } \\
\text { energy }\end{array}$ & $\begin{array}{r}\text { Energy conser- } \\
\text { vation law } \\
\end{array}$ & Power & Collision & Total \\
\hline Remembering & 1 & 1 & 1 & 1 & & & 4 \\
\hline Understanding & 1 & 1 & 1 & 1 & 1 & & 5 \\
\hline Applying & 1 & 2 & 1 & 2 & 1 & 1 & 8 \\
\hline Analyzing & & & & 1 & & 2 & 3 \\
\hline Total & 3 & 4 & 3 & 5 & 2 & 3 & 20 \\
\hline
\end{tabular}

Table 1 shows that items of "remembering", "understanding", and "applying" comprised $85 \%$ of the total score (17 of 20 items) and $15 \%$ of the total score on the item of "analyzing" ( 3 of 20 items).

\subsubsection{Validity of instrument}

Expert opinion was obtained from physics educators and science education lecture so as to attain content validity. The items were assessed by a group of experts in science education and physics for the appropriateness of the items for the purpose of the investigation and representativeness of the energy topic. The required modifications were made in accordance with experts' recommendations. The test was applied to both EG and CG for pretest and posttest.

\subsubsection{Reliability of instrument}

The instrument's reliability was determined by adopting the Kuder-Richardson 21 formula. This instrument was conducted with a pilot study for 45 first year students, who were not part of the study. The data were analyzed using Kuder - Richardson 21 formula, a reliability index with reliability coefficient of 0,65 , which proved that the instrument was reliable and thus suitable for the study. 


\subsubsection{Data collection}

The pretest using this instrument was administered to both experimental and control group for 45 minutes before the intervention. After the pretest was over, the experimental group was taught using feedback and formative assessment on the energy topic for six teaching hours. For the control group, the same content knowledge was delivered not using feedback and formative assessment strategy for the same duration. Both the groups were then administered with the posttest that comprised of 20 items but reshuffled items for 45 minutes.

\subsection{Tool for data analysis}

The software SPSS 22 was used in this study. The data were collected before and after applying of SRS for feedback and formative assessment. Kolmogorov-Smirnov Test was used to evaluate the normal distribution of the data. The fact that $\mathrm{p}$-value was over 0,05 was considered as evidence of the normal distribution of the data as seen in Table 2.

Table 2. Test of the normal distribution for pretest and posttest

\begin{tabular}{lrrr}
\hline & Stastic & df & p \\
\hline Pretest & 0,872 & 148 & 0,371 \\
Posttest & 0,853 & 148 & 0,524 \\
\hline
\end{tabular}

The data collected were analyzed using independent T-test. The means of the pretest and posttest for both the groups were determined to compare the learning goals on energy topic for the experimental group that was taught using feedback and formative assessment and the control group was taught not using feedback and formative assessment based SRS.

\section{RESULTS}

Data collected from the pretest were computed statistically. The results of the statistical computing are presented below.

Table 3. Pretest mean score of the control group and experiemental group

\begin{tabular}{lrllrr}
\hline Test Group & N Mean & SD & t & $\begin{array}{r}\text { Sig. (2- } \\
\text { tailed) }\end{array}$ \\
\hline Experimental & 75 & 4,69 & $1,26-2,04$ & 0,839 \\
Control & 73 & 4,74 & 1,50 & \\
\hline
\end{tabular}

As seen in Table 3, there is not statistically significant difference in mean score of experimental group ( $\mathrm{M}=4,69 ; \mathrm{SD}=1,26)$ and control group ( $\mathrm{M}=4,74 ; \mathrm{SD}=1,50, \mathrm{t}(146)=-2,04, \mathrm{p}=0,839)$. Since the calculated p-value was greater than 0,05
( $>>0,05)$. Hence, it was concluded that both groups were homogeneous in learning ability based on the energy topic prior to the intervention.

Table 4. Posttest mean score of the control group and experiemental group

\begin{tabular}{lccccr}
\hline Test Group & N Mean & SD & $\begin{array}{r}\text { Sig. (2- } \\
\text { tailed) }\end{array}$ \\
\hline Experimental & 75 & 6,68 & 1,67 & 2,46 & 0,015 \\
Control & 73 & 6,00 & 1,68 & & \\
\hline
\end{tabular}

As seen in Table 4, there is statistically significant difference in mean score of experimental group (M $=6,68 ; \mathrm{SD}=1,67)$ and control group $(\mathrm{M}=6,00$; $\mathrm{SD}=1,68, \mathrm{t}(146)=2,46, \mathrm{p}=0,015)$. Since the calculated p-value was smaller than $0,05(\mathrm{p}<0,05)$. Hence, it was indicated that using computer based formative assessment with SRS enhance the students'ability learning for experimental group.

\section{DISCUSSION}

Using the SRS system via google form as a tool for feedback and formative assessment was likely to enhance student learning. The formative feedback is crucial for improving knowledge, skill, and is also a significant factor in motivating student learning in order to help students meet the desired learning goals.

Finding from this research is consistent with the work of Weldmeskel and Michael (2016). In their research, they asserted that feedback and formative assessment based SRS facilitate students to involve in their self-regulated learning process with a view to meet desired learning goals. Besides, using SRS has enhanced classroom interaction, students become more participatory, interactive and engaged in the learning process (Heaslip et al., 2013). Moreover, to avoid students' attention drops in the classroom, teachers use SRS to keep students engaged and attentive in the classroom (Caldwell, 2007).

Finding from the study demonstrated that using SRS for formative assessment improved students' test scores. It was explained that SRS involved students in virtual learning, provided real-time feedback for both students and teachers in an online course: on part of students, prompt feedback from teacher helped them to reconsider the misconcepts or misunderstanding. Moreover, students also regulated their learning experience by means of this feedback. On part of teacher, real-time feedback helped instructor to monitor and improve students' progress 
level during the learning. Besides, SRS was used during teaching and learning: SRS was used before each lesson to review prior knowledge. During the lesson, SRS was applied to check if students understand each concept. After the lesson, SRS was used as a summary check of key concepts. In addition, SRS also made students reflect on errors and commented on them with other students in the classroom.

In virtual classroom, applying the SRS to technology device i.e., computer, smartphone with internet connection for feedback and formative assessment is useful. The teacher can use the SRS not only for checking students' prior knowledge to choose a teaching strategy but also for supporting students lacking basic knowledge before each lecture. Using the SRS for feedback and formative assessment helps students to master key concepts before transferring them into solving complex problems.

\section{CONCLUSIONS}

This study aimed to apply the SRS to technology i.e., computer, smartphone with internet connection for feedback and formative assessment to enhance students' learning outcomes. The finding of the study demonstrated that the SRS improved students' effective learning, helped student meet learning goals. The experimental group, in which SRS was applied, got better results than the control group, who did not apply it. Results show using SRS for feedback and formative assessment is very meaningful not only for students also for teachers.

\section{REFERENCES}

Beatty, I. D., \& Gerace, W. J. (2009). Technology-enhanced formative assessment: A research-based pedagogy for teaching science with classroom response technology. Journal of Science Education and Technology, 18(2), 146-162.

Caldwell, J. E. 2007. Clickers in the large classroom: Current research and best-practice tips. $C B E-$ Life Sciences Education, 6(1), 9-20.

Clark, I. 2012. Formative assessment: Assessment is for self-regulated learning. Educational Psychology Review, 24(2), 205-249.
Dixson, Dante D., and Frank C. Worrell. 2016. Formative and Summative Assessment in the Classroom. Theory Into Practice, 55(2), 153-59.

Elmahdi, I., Al-Hattami, A., \& Fawzi, H. (2018). Using Technology for Formative Assessment to Improve Students' Learning. Turkish Online Journal of Educational Technology - TOJET, 17(2), 182-188.

Hattie, J. (2012). Visible learning for teachers: Maximizing impact on learning. Abingdon: Routledge, 281 pages.

Heaslip, G., Donovan, P., \& Cullen, J. G. 2014. Student response systems and learner engagement in large classes. Active Learning in Higher Education, 15(1), 11-24.

Ngo Van Thien. (2017). Impact of formative assessment on academic achievement. Ho Chi Minh City University of Education Journal of Science, 14(2), 131-140.

Panadero, E., Broadbent, J., Boud, D., \& Lodge, J. M. 2019. Using formative assessment to influence selfand co-regulated learning: The role of evaluative judgement. European Journal of Psychology of Education, 34(3), 535-557.

Sahin, M. 2019. Classroom Response Systems as a Formative Assessment Tool: Investigation into Students' Perceived Usefulness and Behavioural Intention. International Journal of Assessment Tools in Education, 6(4), 693-705.

Siau, K., Sheng, H., \& Nah, F.-H. 2006. Use of a classroom response system to enhance classroom interactivity. IEEE Transactions on Education, 49(3), 398-403.

Spector, J. M., Ifenthaler, D., Sampson, D., Yang, L. (Joy), Mukama, E., Warusavitarana, A., Dona, K. L., Eichhorn, K., Fluck, A., \& Huang, R. (2016). Technology enhanced formative assessment for 21 st century learning. Educational Technology \& Society, 19(3), 58-71.

Weldmeskel, F. M., \& Michael, D. J. 2016. The impact of formative assessment on self-regulating learning in university classrooms. Tuning Journal for Higher Education, 4(1), 99-118.

Wiggins, G., \& McTighe, J. 1998. What is backward design. Understanding by Design. 1, 7-19.

Wiliam, D. 2011. Embedded formative assessment. Bloomington: Solution Tree Press, 218 pages. 